\title{
Resveratrol enhances the antimicrobial effect of polymyxin B on Klebsiella pneumoniae and Escherichia coli isolates with polymyxin B resistance
}

\author{
$\mathrm{Li} \mathrm{Liu}^{1 \dagger}$, Jingyi Yu ${ }^{1 \dagger}$, Xiaofei Shen ${ }^{2}$, Xingwei Cao ${ }^{3}$, Qing Zhan ${ }^{4}$, Yinjuan Guo ${ }^{5,6}$ and Fangyou Yu $u^{5,6^{*}}$ (D)
}

\begin{abstract}
Background: Multidrug resistant (MDR) Gram-negative bacterial infections are a serious threat to human health due to the lack of effective treatments. In this study, we selected 50 Gram-negative bacterial strains, including 26 strains of Klebsiella pneumoniae and 24 strains of Escherichia coli, to explore whether resveratrol and polymyxin B have a synergistic killing effect.

Results: MIC values against polymyxin B were $\geq 4 \mu \mathrm{g} / \mathrm{mL}$ for 44 of the strains and were $2 \mu \mathrm{g} / \mathrm{mL}$ for the other 6 strains. MICs against polymyxin B in the isolates tested were significantly reduced by the addition of resveratrol. The degree of decline depended on the bacteria, ranging from 1/2 MIC to 1/512 MIC, and the higher the concentration of resveratrol, the greater the decrease. Checkerboard analysis indicated a synergistic effect between resveratrol and polymyxin B; the optimal drug concentration for different bacteria was different, that of resveratrol ranging from $32 \mu \mathrm{g} / \mathrm{mL}$ to $128 \mu \mathrm{g} / \mathrm{mL}$. Subsequent time-kill experiments showed that a combination of polymyxin B and resveratrol was more effective in killing bacteria.
\end{abstract}

Conclusions: Our in vitro studies have shown that resveratrol can increase the sensitivity of MDR bacterial strains to polymyxin B, suggesting a potential new approach to the treatment of MDR infections.

Keywords: Polymyxin B, Resveratrol, Combination therapy, Multidrug resistance (MDR)

\section{Background}

In recent years, the emergence of Gram-negative bacteria that are resistant to multiple antibiotics has put a lot of pressure on healthcare centers around the world [1]. Infections caused by multidrug-resistant (MDR) Gram-negative bacteria not only have a higher mortality rate [2], but also impose greater economic burdens than

\footnotetext{
*Correspondence: wzjxyfy@163.com

${ }^{\dagger} \mathrm{Li}$ Liu and Jingyi Yu contributed equally to this work.

${ }^{5}$ Department of Clinical Laboratory Medicine, Shanghai Pulmonary Hospital, Tongji University School of Medicine, Shanghai 200082, China

${ }^{6}$ Shanghai Key Laboratory of Tuberculosis, Shanghai Pulmonary Hospital,

Tongji University School of Medicine, Shanghai 200082, China

Full list of author information is available at the end of the article
}

infections caused by susceptible Gram-negative bacteria [3]. New antibiotics or more effective therapies are therefore urgently needed to solve this problem. In many situations, colistin and polymyxin B are considered the last antibiotics of choice [4].

Polymixin B has high affinity for the lipopolysaccharides (LPS) of Gram-negative bacilli and has been re-applied in the clinic. Polymixin B induces LPS aggregation, increasing the charge on cell membrane surfaces, and making it internalize and bind to the cell membrane, resulting in the leakage of cell contents [5]. Polymyxin B interacts directly with the lipid A component of lipopolysaccharide, thereby increasing the permeability of bacterial cell membranes

(C) The Author(s). 2020 Open Access This article is licensed under a Creative Commons Attribution 4.0 International License, which permits use, sharing, adaptation, distribution and reproduction in any medium or format, as long as you give appropriate credit to the original author(s) and the source, provide a link to the Creative Commons licence, and indicate if changes were made. The images or other third party material in this article are included in the article's Creative Commons licence, unless indicated otherwise in a credit line to the material. If material is not included in the article's Creative Commons licence and your intended use is not permitted by statutory regulation or exceeds the permitted use, you will need to obtain permission directly from the copyright holder. To view a copy of this licence, visit http://creativecommons.org/licenses/by/4.0/ The Creative Commons Public Domain Dedication waiver (http://creativecommons.org/publicdomain/zero/1.0/) applies to the data made available in this article, unless otherwise stated in a credit line to the data. 
[6]. Plasmids carrying anti-polymyxin B genes, including $m c r-1, m c r-2$ and $m c r-3$, have been reported [7]; however, polymyxin combination therapy can improve bacterial killing and prevent the emergence of drug resistance [8].

Resveratrol is a natural polyphenolic compound that is found in large amounts in grapes, peanuts, and other plant sources, and in red wine [9]. Reports indicate that resveratrol can be used as a phytoalexin against fungal infections, and that it is a promising multi-target anticancer drug for the prevention and treatment of cancer [10-12]. Recent studies have demonstrated that it has potent antibacterial activity [13], and that it can significantly enhance the effect of aminoglycoside antibiotics (such as tobramycin, gentamicin, amikacin and netilmicin) on Pseudomonas aeruginosa biofilms [14]. Studies have shown that resveratrol can inactivate ATP synthase, thereby enhancing the sensitivity of S.aureus to polymyxin B [15].

In this study, we selected 50 strains of $K$. pneumoniae (Klebsiella pneumoniae) and E. coli (Escherichia coli) to study whether resveratrol and polymyxin $B$ have synergistic effects.

\section{Results}

\section{Bacterial isolates}

We selected the strains for this study from a hospital in 2018, and screened out the experimental strains using drug sensitivity tests. We selected 50 multi-drug resistant strains (26 strains of $K$. pneumoniae and 24 strains of $E$. coli) for analysis (Table 1); six strains were sensitive to polymyxin B, and 44 strains were resistant. Resistance to polymyxin B was divided into two major categories, either due to an $m c r-1$ gene carrying plasmid, or due to other reasons. Resistance to polymyxin B in E. coli was due to the $m c r-1$ gene, while only one strain of resistant $K$. pneumoniae carried the $m c r-1$ gene, the reasons for resistance in the other strains being unknown.

\section{Resveratrol may be able to increase sensitivity to polymyxin B}

Table 1 shows the MIC values of the 50 strains against polymyxin $\mathrm{B}$ and resveratrol. The MIC value against resveratrol in all strains was $\geq 512 \mu \mathrm{g} / \mathrm{mL}$, and the MICs of polymyxin $B$ it were reduced in all strains after the addition of resveratrol. In $K$. pneumoniae, after adding $32 \mu \mathrm{g} / \mathrm{mL}$ of resveratrol, in addition to the sensitive strains, strain 15 and strain 2 were highly resistant to polymyxin B, their MIC values for polymyxin B being decreased. The range of the drop was from $1 / 2$ MIC to $1 / 8$ MIC. When 64 or $128 \mu \mathrm{g} / \mathrm{mL}$ of resveratrol was added, the MIC values of polymyxin B against all strains decreased, and the degree of decline increased with increasing concentration of resveratrol. The situation observed in E. coli was very similar to that observed in K. pneumoniae; resveratrol seems to have a similar effect on different strains, regardless of the source of the strain and the cause of resistance to polymyxin $B$. This suggests that resveratrol may be able to increase the sensitivity of strains to polymyxin B (Table 1).

\section{Polymyxin B and resveratrol have a synergistic effect}

Chequerboard assays can be used to detect synergy between two drugs. The Fractional Inhibitory Concentration (FIC) in the 14 bacterial strains selected for this experiment was less than 0.5 , indicating the presence of a synergistic effect between polymyxin B and resveratrol (Table 2).

\section{Time-killresults of polymyxin B and resveratrol against $K$. pneumoniae and E. coli}

We deduced the optimal concentration of resveratrol combined with polymyxin B from the chequerboard assays. With the exception of strains 12 and 47, the optimal concentration of polymyxin $\mathrm{B}$ for the other 13 bacterial strains tested when the concentration of resveratrol ranged from 32 to $128 \mu \mathrm{g} / \mathrm{mL}$ was $1 / 4$ MIC polymyxin B. At a concentration of $128 \mu \mathrm{g} / \mathrm{mL}$ resveratrol, however, the DMSO in the drug solution exceeded $0.1 \%$ and was toxic to cells. For this reason, we chose the $1 / 4$ MIC polymyxin B and $64 \mu \mathrm{g} / \mathrm{mL}$ intermediate concentration of resveratrol for time-kill experiments (Fig. 1). Some differences were observed between strains. $64 \mu \mathrm{g} /$ $\mathrm{mL}$ resveratrol alone had no killing effect on bacteria. Strains 1 and 7 were killed after $1 \mathrm{~h}$ of treatment with the two drugs $(1 / 4$ MIC polymyxin B and $64 \mu \mathrm{g} / \mathrm{mL}$ resveratrol), strains 3 and 11 after $2 \mathrm{~h}$, and strains 19 and 12 after 4 and $6 \mathrm{~h}$ respectively. Neither of the drugs alone had a significant killing effect on the strains tested. While strains 23 and 47 were not completely killed, the killing effect of the two drugs together was more pronounced in the early time than either drug alone. The number of colonies of these two strains reached the level of the untreated group at $24 \mathrm{~h}$.

\section{Discussion}

In view of the rapid emergence of multi-drug resistance and the general lack of new effective antibiotics developed in the last two decades, new methods for the treatment of MDR Gram-negative bacterial infections are urgently needed $[1,16]$. Polymyxin $B$ is considered to be the last choice of drug for the treatment of multi-drug resistant infections, but bacterial strains resistant to polymyxin B are increasing in prevalence [17]. Many studies have shown that other antibiotics or nonantibiotics combined with polymyxin B can improve its antibacterial activity $[8,18]$. Resveratrol (trans-3,4',5-trihydroxystilbene) is a polyphenolic compound that was first mentioned in an article in 1940 and isolated from the plant cucurbits by root separation [19]. Many reports indicate that resveratrol has an antiviral effect on HIV-1 
Table 1 Strain information and minimum inhibitory concentrations (MIC) of polymyxin B and resveratrol against bacterial isolates in this study

\begin{tabular}{|c|c|c|c|c|c|c|c|}
\hline \multirow[t]{2}{*}{ Isolate } & \multirow[t]{2}{*}{ Source } & \multicolumn{5}{|l|}{ MIC } & \multirow{2}{*}{$\begin{array}{l}\text { Polymyxin } \\
\text { susceptibility } \\
\text { and } \\
\text { mechanism of } \\
\text { resistance } \\
\end{array}$} \\
\hline & & Res & PB & $\begin{array}{l}\text { PB in the presence } \\
\text { of } 32 \mu \mathrm{g} / \mathrm{ml} \text { Res }\end{array}$ & $\begin{array}{l}\text { PB in the presence } \\
\text { of } 64 \mu \mathrm{g} / \mathrm{ml} \text { Res }\end{array}$ & $\begin{array}{l}\text { PB in the presence } \\
\text { of } 128 \mu \mathrm{g} / \mathrm{ml} \text { Res }\end{array}$ & \\
\hline \multicolumn{8}{|c|}{ Klebsiella pneumoniae } \\
\hline 1 & human & 512 & 16 & 8 & 4 & 2 & mcr-1 \\
\hline 2 & human & 512 & $>512$ & $>512$ & 128 & 2 & Uncharacterized \\
\hline 3 & human & 512 & 8 & 2 & 2 & 2 & Uncharacterized \\
\hline 4 & human & $>2048$ & 4 & 2 & 1 & 1 & Uncharacterized \\
\hline 5 & human & $>2048$ & 4 & 2 & 1 & 1 & Uncharacterized \\
\hline 6 & human & 512 & $>512$ & $>512$ & 256 & 8 & Uncharacterized \\
\hline 7 & human & 1024 & 8 & 2 & 2 & 2 & Uncharacterized \\
\hline 8 & human & $>2048$ & $>512$ & 256 & 16 & 1 & Uncharacterized \\
\hline 9 & human & 2048 & 4 & 1 & 0.5 & 1 & Uncharacterized \\
\hline 10 & human & 2048 & 4 & 1 & 1 & 1 & Uncharacterized \\
\hline 11 & human & 512 & 4 & 2 & 2 & 1 & Uncharacterized \\
\hline 12 & human & $>2048$ & 16 & 1 & 1 & 1 & Uncharacterized \\
\hline 13 & human & 2048 & 4 & 2 & 0.5 & 1 & Uncharacterized \\
\hline 14 & human & 2048 & 4 & 2 & 1 & 1 & Uncharacterized \\
\hline 15 & human & 2048 & 16 & 4 & 2 & 1 & Uncharacterized \\
\hline 16 & human & 2048 & 32 & 4 & 4 & 0.5 & Uncharacterized \\
\hline 17 & human & 2048 & 64 & 16 & 4 & 1 & Uncharacterized \\
\hline 18 & human & 512 & 4 & 1 & 0.5 & 0.5 & Uncharacterized \\
\hline 19 & human & $>2048$ & 4 & 1 & 0.5 & 0.5 & Uncharacterized \\
\hline 20 & human & 512 & 256 & 128 & 32 & 1 & Uncharacterized \\
\hline 21 & human & 2048 & 16 & 2 & 2 & 0.5 & Uncharacterized \\
\hline 22 & human & $>2048$ & 2 & 0.5 & 0.5 & 1 & Susceptible \\
\hline 23 & human & 512 & 2 & 1 & 0.5 & 1 & Susceptible \\
\hline 24 & human & 2048 & 2 & 2 & 0.5 & 0.5 & Susceptible \\
\hline 25 & human & $>2048$ & 2 & 1 & 0.5 & 1 & Susceptible \\
\hline 26 & human & $>2048$ & 2 & 1 & 1 & 1 & Susceptible \\
\hline \multicolumn{8}{|c|}{ Escherichia coli } \\
\hline 27 & animal & $>2048$ & 4 & 2 & 2 & 1 & mcr-1 \\
\hline 28 & animal & $>2048$ & 4 & 2 & 2 & 1 & mcr-1 \\
\hline 29 & animal & 2048 & $>512$ & 64 & 8 & 4 & mcr-1 \\
\hline 30 & animal & $>2048$ & 4 & 2 & 2 & 1 & mcr-1 \\
\hline 31 & animal & $>2048$ & 4 & 2 & 2 & 1 & $\mathrm{mcr}-1$ \\
\hline 32 & animal & $>2048$ & $>512$ & $>512$ & 256 & 32 & mcr-1 \\
\hline 33 & animal & $>2048$ & 4 & 2 & 2 & 1 & mcr-1 \\
\hline 34 & animal & $>2048$ & 4 & 2 & 2 & 1 & $\mathrm{mcr}-1$ \\
\hline 35 & animal & 2048 & 4 & 4 & 2 & 1 & mcr-1 \\
\hline 36 & animal & $>2048$ & 4 & 2 & 2 & 1 & mcr-1 \\
\hline 37 & animal & $>2048$ & 4 & 2 & 2 & 1 & mcr-1 \\
\hline 38 & animal & $>2048$ & 4 & 2 & 2 & 1 & $\mathrm{mcr}-1$ \\
\hline 39 & animal & $>2048$ & $>512$ & $>512$ & 128 & 8 & mcr-1 \\
\hline
\end{tabular}


Table 1 Strain information and minimum inhibitory concentrations (MIC) of polymyxin B and resveratrol against bacterial isolates in this study (Continued)

\begin{tabular}{|c|c|c|c|c|c|c|c|}
\hline \multirow[t]{2}{*}{ Isolate } & \multirow[t]{2}{*}{ Source } & \multicolumn{5}{|l|}{ MIC } & \multirow{2}{*}{$\begin{array}{l}\text { Polymyxin } \\
\text { susceptibility } \\
\text { and } \\
\text { mechanism of } \\
\text { resistance }\end{array}$} \\
\hline & & $\operatorname{Res}$ & PB & $\begin{array}{l}\text { PB in the presence } \\
\text { of } 32 \mu \mathrm{g} / \mathrm{ml} \mathrm{Res}\end{array}$ & $\begin{array}{l}\text { PB in the presence } \\
\text { of } 64 \mu \mathrm{g} / \mathrm{ml} \text { Res }\end{array}$ & $\begin{array}{l}\text { PB in the presence } \\
\text { of } 128 \mu \mathrm{g} / \mathrm{ml} \text { Res }\end{array}$ & \\
\hline 40 & animal & 2048 & 32 & 16 & 4 & 1 & mcr-1 \\
\hline 41 & animal & $>2048$ & 4 & 2 & 2 & 1 & mcr-1 \\
\hline 42 & animal & $>2048$ & 4 & 2 & 2 & 1 & mcr-1 \\
\hline 43 & animal & $>2048$ & $>512$ & $>512$ & 256 & 2 & mcr-1 \\
\hline 44 & animal & $>2048$ & 4 & 2 & 2 & 0.5 & mcr-1 \\
\hline 45 & animal & 2048 & 64 & 4 & 4 & 0.5 & mcr-1 \\
\hline 46 & animal & $>2048$ & 4 & 2 & 2 & 0.5 & mcr-1 \\
\hline 47 & human & 2048 & 4 & 1 & 0.5 & 0.5 & mcr-1 \\
\hline 48 & human & $>2048$ & 4 & 2 & 1 & 1 & mcr-1 \\
\hline 49 & animal & 2048 & 32 & 8 & 2 & 1 & Uncharacterized \\
\hline 50 & human & 2048 & 2 & 2 & 1 & 1 & Susceptible \\
\hline
\end{tabular}

$P B$ Stands for polymyxin $B$ and Res stands for resveratrol

[20] and herpes simplex virus [21, 22]. Resveratrol also has antibacterial effects [23]. In this study we explored the difference between resveratrol and polymyxin $B$ combination therapy and monotherapy.

Resistance to polymyxin B in Gram-negative bacilli arises through different mechanisms, including alterations in their lipopolysaccharides, which have an overall negative charge and are the initial targets of polymyxin [24], activation of the PhoP/PhoQ and PmrA/PmrB twocomponent systems (TCS) by environmental stimuli, and specific mutations within the TCS also leads to constitutive activation and subsequent overexpression of the LPS modified gene [25-27]. In addition, the mutation/ inactivation of the $m g r B$ gene leads to the emergence of K. pneumoniae resistance [28]. The role of efflux in polymyxin resistance is unclear, but some studies have shown that efflux pumps are involved $[29,30]$. In recent years, studies have shown that a plasmid-carried $m c r-1$ gene is also involved in polymyxin resistance. The $m c r-1$ gene encodes lipid A phosphoethanolamine transferase, an enzyme that inactivates polymyxin [31]. In general, polymyxin B drug resistance mechanisms are divided into two major classes: plasmid $m c r-1$ mediated and non-plasmid mediated.

In this study, we found that combination therapy with polymyxin $B$ and resveratrol is much more effective than monotherapy of either drug. MIC values are an indicator of drug activity. Our study found that the drug concentrations of polymyxin $\mathrm{B}$ and resveratrol required for combination therapy were much lower than those required for monotherapy. The combination of the two drugs had a similar effect on polymyxin B sensitive and resistant strains of $K$. pneumoniae and E. coli, suggesting that combination therapy with resveratrol and polymyxin B may have a relatively universal applicability. Checkerboard assays can be used to determine whether there is synergy between drugs. The FIC index of resveratrol and polymyxin B in the 14 strains selected for checkerboard analysis in our study (Table 2) was less than or equal to 0.5 , indicating that resveratrol and polymyxin B have a synergistic antibacterial effect. The purpose of combination therapy is to increase the ability of the drugs to kill the bacteria, achieving a synergistic effect that the two antibiotics do not have when used alone [32]. We performed a time-kill experiment on 8 bacterial strains, finding that 6 of the strains were completely killed after $24 \mathrm{~h}$ of combined use of the two drugs. The growth of strains treated with monotherapies of the two drugs was almost the same as that of the untreated group. Although regrowth occurred in two strains resistant to polymyxin $\mathrm{B}$, the combination of the two drugs still enhanced the initial bacterial killing and may thus help to remove bacteria from the body [8]. Our findings together indicate that the combination of polymyxin B and resveratrol significantly enhances bacterial killing. This is similar to the results of previous studies that resveratrol can enhance the sensitivity of S.aureus to polymyxin B [15].We speculate that resveratrol may destroy the cell envelope, allowing polymyxin $B$ to bind to more targets in the bacterial outer membrane.

\section{Conclusions}

In summary, our study has revealed a synergistic effect between resveratrol and polymyxin B. Resveratrol can increase the sensitivity of multi-drug resistant $K$. pneumoniae and E. coli to polymyxin B, enhancing the killing 
Table 2 FIC index values for polymyxin B and resveratrol against MDR bacterial isolates

\begin{tabular}{lllll}
\hline Isolate & FIC of Polymyxin B & FIC of Resveratrol & FIC index & Interpretation \\
\hline 1 & 0.25 & 0.125 & 0.375 & Synergistic \\
3 & 0.25 & 0.125 & 0.375 & Synergistic \\
5 & 0.25 & 0.125 & 0.375 & Synergistic \\
7 & 0.25 & 0.03125 & 0.28125 & Synergistic \\
10 & 0.25 & 0.0625 & 0.3125 & Synergistic \\
11 & 0.25 & 0.125 & 0.375 & Synergistic \\
12 & 0.125 & $<0.0625$ & $<0.1875$ & Synergistic \\
15 & 0.125 & 0.03125 & 0.15625 & Synergistic \\
18 & 0.25 & 0.0625 & 0.3125 & Synergistic \\
19 & 0.25 & 0.0625 & 0.3125 & Synergistic \\
22 & 0.25 & 0.0625 & 0.3125 & Synergistic \\
23 & 0.25 & 0.25 & 0.5 & Synergistic \\
47 & 0.125 & 0.0625 & 0.1875 & Synergistic \\
50 & 0.25 & 0.03125 & 0.28125 & Synergistic \\
\hline
\end{tabular}

power of polymyxin B. We have only drawn a preliminary conclusion. Further experiments will be needed to substantiate our conclusion. Our findings may provide a potential method for the clinical treatment of multi-drug resistant Gram-negative bacilli infections. Further investigations of why resveratrol has different effects on polymyxin $B$ sensitive and resistant strains and on the different causes of polymyxin B resistance are warranted.

\section{Materials and methods}

\section{Bacteria strains and reagents}

The strains used in this study were isolated from clinical samples and from animals, and included 26 strains of $K$. pneumoniae and 24 strains of E. coli. These strains were isolated from the First Affiliated Hospital of Wenzhou Medical University. Polymyxin B and resveratrol powder were purchased from Solarbio (Beijing, China). Polymyxin B and resveratrol were dissolved in deionized water and dimethyl sulfoxide (DMSO) to prepare stock solutions with a final concentration of $10 \mathrm{mg} / \mathrm{mL}$ and $100 \mathrm{mg} / \mathrm{mL}$, respectively, and sterilized using a $0.20-\mu \mathrm{m}$ cellulose acetate syringe filter. The stock solution was stored at $-20^{\circ} \mathrm{C}$ for no more than 1 month.

\section{MIC assays}

MIC determinations were performed by the broth microdilution method according to the Clinical and Laboratory Standards Association (CLSI) protocol [33]. MICs were determined in 96-well microtiter plates using freshly prepared Mueller-Hinton broth (Solarbio, Beijing, China). The final volume of bacterial samples was $200 \mu \mathrm{l}$, and the bacterial concentration was $5 \times 10^{\wedge 5}$ $\mathrm{CFU} / \mathrm{ml}$. Microtiter plates were read visually after incubation at $37^{\circ} \mathrm{C}$ for $20 \mathrm{~h}$. E. coli ATCC 25922 was used as an internal quality control strain. As resveratrol has no CLSI breakpoint, and the CLSI breakpoint of $K$. pneumoniae and $E$. coli to polymyxin B has not yet been established by CLSI, therefore, the European Antimicrobial Susceptibility Testing Committee (EUCAST) showed that the breakpoint of Enterobacter to polymyxin B is $2 \mu \mathrm{g} / \mathrm{mL}$ (European Antimicrobial Susceptibility Testing Committee [EUCAST], 2020).

\section{Chequerboard assays}

96-well sterile microplates were used for the checkerboard dilution assays. Each antibacterial drug was diluted with bactericidal $\mathrm{MH}$ broth to a maximum concentration of 2times the MIC concentration of the drug. Eight concentrations of each drug were prepared by dilution. Fifty microliters of the appropriate drug dilution was added to the wells of the plates, together with $100 \mu \mathrm{l}$ of the bacterial solution (giving a final inoculum of $5 \times 10^{5} \mathrm{CFU} / \mathrm{mL}$ ). MICs were recorded as the minimum drug concentration without bacterial growth. The interaction between the drugs was judged by calculating the FIC index according to the formula: $\mathrm{FIC}$ index $=\mathrm{FIC}_{(\text {drug } \mathrm{A})}+\mathrm{FIC}_{(\text {drug B) }}$, where $\mathrm{FIC}=$ the MIC of the drug when in the combination/MIC of drug tested individually. FIC index values were interpreted as follows: "synergistic effects" = FIC index $\leq 0.5$, "antagonism" = FIC index >4.0, and "no interaction" = FIC index $>0.5-4.0$ [34].

\section{Time-kill assays}

Time killing experiments were performed using a slightly modified method [8]. Briefly, bacteria were grown overnight in $20 \mathrm{~mL}$ MHB (Mueller-Hinton Broth). The overnight broth culture was transferred to $20 \mathrm{~mL}$ of fresh 


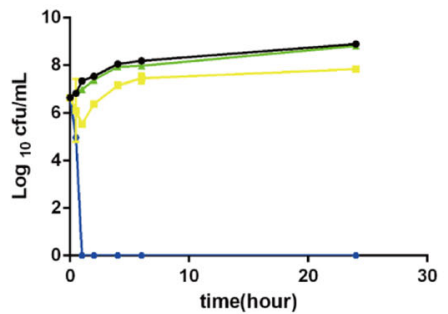

7

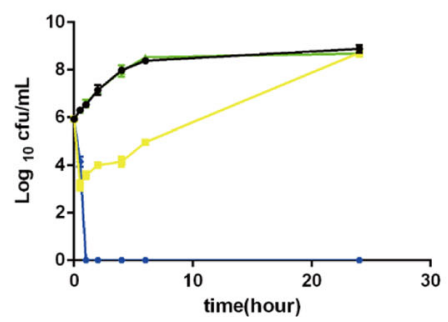

12

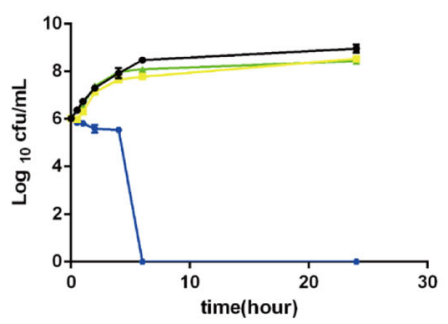

23

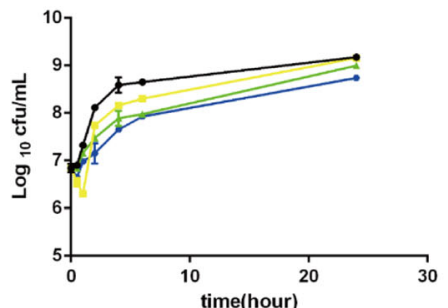

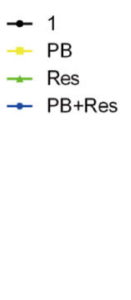

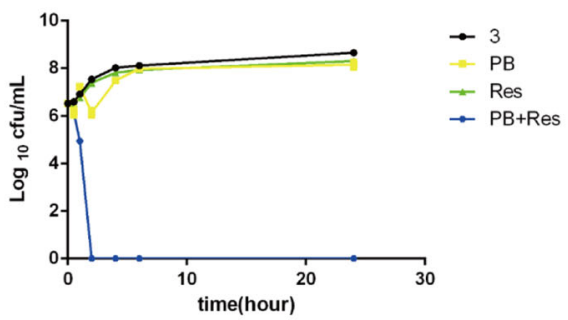

11
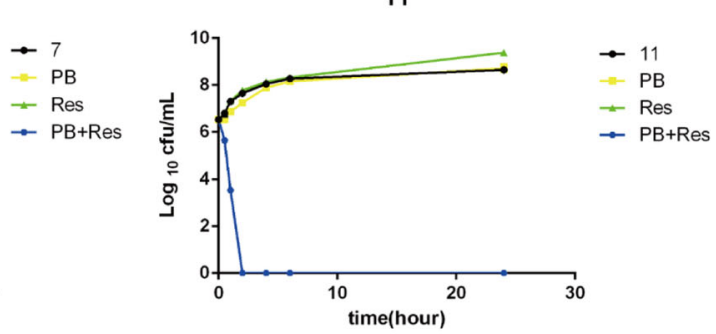

19
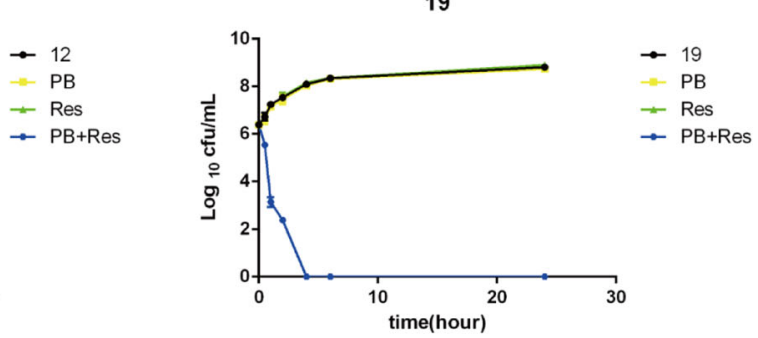

47
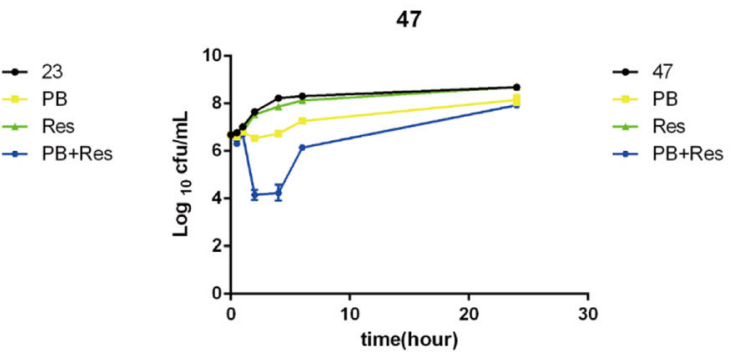

Fig. 1 Time-kill experiments. Bacterial colony forming units in the absence of drug, and in the presence of 1/4 MIC polymyxin B, in the presence of $64 \mathrm{\mu g} / \mathrm{ml}$ resveratrol and in the presence of both drugs, after different periods of incubation $\mathrm{PB}=$ polymyxin $\mathrm{B}$, Res = resveratrol. Data presented are $\log _{10} \mathrm{CFU} / \mathrm{mL}$ mean values from the results of two independent experiments. Error bars represent standard deviations. Results for all 8 strains tested are presented (strain numbers are given above each figure panel)

MHB at a dilution of 50-100 fold and incubated for an additional $3-4 \mathrm{~h}$ to produce log phase cultures of about 0.55 McFarland units. Log phase cultures were transferred to borosilicate glass tubes (to minimize non-specific binding to the plastic resulting in drug loss), diluted approximately 100 -fold, and then transferred to $5 \mathrm{~mL}$ of fresh MHB for treatment. Polymyxin B, resveratrol or both compounds were added to the tubes as appropriate so that the final concentration of polymyxin B reached $2 \mu \mathrm{g} / \mathrm{ml}$, and the final concentration of resveratrol reached $64 \mu \mathrm{g} /$ ml. Samples were removed aseptically at 0, 0.5, 1, 2, 4, 6 and $24 \mathrm{~h}$, serially diluted with physiological saline, and $10 \mu \mathrm{l}$ of the bacterial sample was dropped on a blood agar plate. Colonies were counted after incubation at $37^{\circ} \mathrm{C}$ for $24 \mathrm{~h}$. Combinations of polymyxin B and resveratrol were considered synergistic if the bacteria kill $\geq 2 \quad \log _{10}$ compared to the most effective monotherapy.

\section{Determination of $\mathrm{mcr}-1$ gene}

The polymerase chain reaction was used to amplify the $m c r-1$ gene from each bacterial strain and the product was sent for commercial sequencing analysis. Sequencing 
results were compared and analyzed (Tsingke, Beijing, China), and $m c r-1$ positive and negative strains were identified. Primers used in the experiment were $m c r-1-\mathrm{F}\left(5^{\prime}-\right.$ ATCAGCCAAACCTATCCC-3') and mor-1-R (5'TAGACACCGTTCTCACCC-3').

\author{
Abbreviations \\ K. pneumoniae: Klebsiella pneumoniae; E. coli: Escherichia coli; MIC: Minimum \\ inhibitory concentration; LPS: Lipopolysaccharide; DMSO: Dimethyl sulfoxide; \\ CLSI: Clinical and Laboratory Standards Institute; EUCAST: European \\ Antimicrobial Susceptibility Testing Committee; FIC: Fractional inhibitory \\ concentration; MHB: Mueller-Hinton Broth; TSB: Tryptic Soy Broth; \\ PBS: Phosphate buffer solution; OD: Optical density; CFU: Colony-Forming \\ Units
}

\section{Acknowledgements}

The authors are grateful to the First Affiliated Hospital of Wenzhou Medical University.

\section{Authors' contributions}

$L L, X S$, JY, and $X C$ designed the study and analyzed and interpreted the data. QZ and LL drafted the manuscript and revised it critically for important intellectual content. FY provided approval for the publication of the content. YG participated in the experimental design and data analysis. FY agrees to be accountable for all aspects of the work, ensuring that questions related to the accuracy or integrity of any part of the work are appropriately investigated and resolved. All authors read and approved the final manuscript.

\section{Funding}

This study was supported by grants from the Natural Science Fund of China (81672078) and the Jiangxi Provincial Department of Science and Technology, China (20181BBG70030) covering the each section of this study, including the design of the study and collection, analysis, and interpretation of the data and manuscript preparation.

\section{Availability of data and materials}

The datasets generated during the current study are available from the corresponding author upon reasonable request. Most of the data is included in this published article.

\section{Ethics approval and consent to participate}

The Ethics Committee of the first Affiliated Hospital of Wenzhou Medical University exempted this study from review because the present study focused on bacteria.

\section{Consent for publication}

Not applicable.

\section{Competing interests}

The authors declare they have no competing interests.

\section{Author details}

'Department of Laboratory Medicine, The First Affiliated Hospital of Wenzhou Medical University, Wenzhou 325000, China. ${ }^{2}$ Department of Respiratory Medicine, The First Affiliated Hospital of Wenzhou Medical University, Wenzhou 325000, China. ${ }^{3}$ Jiangxi Provincial Key Laboratory of Medicine, Clinical Laboratory of the Second Affiliated Hospital of Nanchang University, Nanchang 330006, China. ${ }^{4}$ Jiangxi Provincial Key Laboratory of Preventive Medicine, Nanchang University, Nanchang 330006, China. ${ }^{5}$ Department of Clinical Laboratory Medicine, Shanghai Pulmonary Hospital, Tongji University School of Medicine, Shanghai 200082, China. ${ }^{6}$ Shanghai Key Laboratory of Tuberculosis, Shanghai Pulmonary Hospital, Tongji University School of Medicine, Shanghai 200082, China.
Received: 12 June 2020 Accepted: 1 October 2020

Published online: 12 October 2020

\section{References}

1. Boucher HW, Talbot GH, Benjamin DK Jr, Bradley J, Guidos RJ, Jones RN, Murray BE, Bonomo RA, Gilbert D, Infectious Diseases Society of A. 10 x '20 Progress--development of new drugs active against gram-negative bacilli: an update from the Infectious Diseases Society of America. Clin Infect Dis. 2013:56(12):1685-94

2. Harris $P$, Paterson $D$, Rogers $B$. Facing the challenge of multidrug-resistant gram-negative bacilli in Australia. Med J Aust. 2015;202(5):243-7.

3. Gandra S, Barter DM, Laxminarayan R. Economic burden of antibiotic resistance: how much do we really know? Clin Microbiol Infect. 2014; 20(10):973-80.

4. Poirel L, Jayol A, Nordmann P. Polymyxins: antibacterial activity, susceptibility testing, and resistance mechanisms encoded by plasmids or chromosomes. Clin Microbiol Rev. 2017;30(2):557-96.

5. Domingues MM, Inacio RG, Raimundo JM, Martins M, Castanho MA, Santos NC. Biophysical characterization of polymyxin B interaction with LPS aggregates and membrane model systems. Biopolymers. 2012;98(4):338-44.

6. Velkov T, Roberts KD, Thompson PE, Li J. Polymyxins: a new hope in combating gram-negative superbugs? Future Med Chem. 2016;8(10):1017-25.

7. Kluytmans J. Plasmid-encoded colistin resistance: mcr-one, two, three and counting. Euro Surveill. 2017;22(31):30588.

8. Tran TB, Wang J, Doi Y, Velkov T, Bergen PJ, Li J. Novel polymyxin combination with antineoplastic mitotane improved the bacterial killing against polymyxin-resistant multidrug-resistant gram-negative pathogens. Front Microbiol. 2018;9:721.

9. Biesalski HK. Polyphenols and inflammation: basic interactions. Curr Opin Clin Nutr Metab Care. 2007;10(6):724-8.

10. Carlson A, Alderete KS, Grant MKO, Seelig DM, Sharkey LC, Zordoky BNM. Anticancer effects of resveratrol in canine hemangiosarcoma cell lines. Vet Comp Oncol. 2018;16(2):253-61.

11. Zhao Y, Tang H, Zeng X, Ye D, Liu J. Resveratrol inhibits proliferation, migration and invasion via Akt and ERK1/2 signaling pathways in renal cell carcinoma cells. Biomed Pharmacother. 2018;98:36-44.

12. Udenigwe CC, Ramprasath VR, Aluko RE, Jones PJ. Potential of resveratrol in anticancer and anti-inflammatory therapy. Nutr Rev. 2008;66(8):445-54.

13. Vestergaard $\mathbf{M}$, Ingmer $\mathrm{H}$. Antibacterial and antifungal properties of resveratrol. Int J Antimicrob Agents. 2019;53(6):716-23.

14. Zhou JW, Chen TT, Tan XJ, Sheng JY, Jia AQ. Can the quorum sensing inhibitor resveratrol function as an aminoglycoside antibiotic accelerant against Pseudomonas aeruginosa? Int J Antimicrob Agents. 2018;52(1):35-41.

15. Liu L, Beck C, Nohr-Meldgaard K, Peschel A, Kretschmer D, Ingmer H, Vestergaard M. Inhibition of the ATP synthase sensitizes Staphylococcus aureus towards human antimicrobial peptides. Sci Rep. 2020;10(1):11391.

16. Boucher HW, Talbot GH, Bradley JS, Edwards JE, Gilbert D, Rice LB, Scheld M, Spellberg B, Bartlett J. Bad bugs, no drugs: no ESKAPE! An update from the Infectious Diseases Society of America. Clin Infect Dis. 2009;48(1):1-12.

17. Olaitan $\mathrm{AO}$, Morand S, Rolain JM. Mechanisms of polymyxin resistance: acquired and intrinsic resistance in bacteria. Front Microbiol. 2014;5:643.

18. Hussein M, Han ML, Zhu Y, Zhou QT, Lin YW, Hancock REW, Hoyer D, Creek DJ, Li J, Velkov T. Metabolomics study of the synergistic killing of polymyxin $B$ in combination with amikacin against polymyxin-susceptible and -resistant Pseudomonas aeruginosa. Antimicrob Agents Chemother. 2019; 64(1):e01587-19. https://doi.org/10.1128/AAC.01587-19.

19. Aggarwal BB, Bhardwaj A, Aggarwal RS, Seeram NP, Shishodia S, Takada Y. Role of resveratrol in prevention and therapy of cancer: preclinical and clinical studies. Anticancer Res. 2004;24(5A):2783-840.

20. Heredia A, Davis C, Redfield R. Synergistic inhibition of HIV-1 in activated and resting peripheral blood mononuclear cells, monocyte-derived macrophages, and selected drug-resistant isolates with nucleoside analogues combined with a natural product, resveratrol. J Acquir Immune Defic Syndr. 2000;25(3):246-55.

21. Docherty JJ, Smith JS, Fu MM, Stoner T, Booth T. Effect of topically applied resveratrol on cutaneous herpes simplex virus infections in hairless mice. Antivir Res. 2004;61(1):19-26.

22. Docherty JJ, Fu MM, Stiffler BS, Limperos RJ, Pokabla CM, DeLucia AL. Resveratrol inhibition of herpes simplex virus replication. Antivir Res. 1999;43(3):145-55.

23. Chan MM. Antimicrobial effect of resveratrol on dermatophytes and bacterial pathogens of the skin. Biochem Pharmacol. 2002;63(2):99-104. 
24. Moffatt JH, Harper M, Harrison P, Hale JD, Vinogradov E, Seemann T, Henry R, Crane B, St Michael F, Cox AD, et al. Colistin resistance in Acinetobacter baumannii is mediated by complete loss of lipopolysaccharide production. Antimicrob Agents Chemother. 2010:54(12):4971-7.

25. Gunn JS, Ryan SS, Van Velkinburgh JC, Ernst RK, Miller SI. Genetic and functional analysis of a PmrA-PmrB-regulated locus necessary for lipopolysaccharide modification, antimicrobial peptide resistance, and oral virulence of Salmonella enterica serovar typhimurium. Infect Immun. 2000; 68(11):6139-46.

26. Gunn JS, Miller SI. PhoP-PhoQ activates transcription of pmrAB, encoding a two-component regulatory system involved in Salmonella typhimurium antimicrobial peptide resistance. J Bacteriol. 1996;178(23):6857-64.

27. Barrow $\mathrm{K}$, Kwon DH. Alterations in two-component regulatory systems of phoPQ and pmrAB are associated with polymyxin $B$ resistance in clinical isolates of Pseudomonas aeruginosa. Antimicrob Agents Chemother. 2009; 53(12):5150-4.

28. Cannatelli A, D'Andrea MM, Giani T, Di Pilato V, Arena F, Ambretti S, Gaibani P, Rossolini GM. In vivo emergence of colistin resistance in Klebsiella pneumoniae producing KPC-type carbapenemases mediated by insertional inactivation of the PhoQ/PhoP mgrB regulator. Antimicrob Agents Chemother. 2013;57(11):5521-6.

29. Srinivasan VB, Rajamohan G. KpnEF, a new member of the Klebsiella pneumoniae cell envelope stress response regulon, is an SMR-type efflux pump involved in broad-spectrum antimicrobial resistance. Antimicrob Agents Chemother. 2013;57(9):4449-62.

30. Padilla E, Llobet E, Domenech-Sanchez A, Martinez-Martinez L, Bengoechea JA, Alberti S. Klebsiella pneumoniae AcrAB efflux pump contributes to antimicrobial resistance and virulence. Antimicrob Agents Chemother. 2010; 54(1):177-83.

31. Liu YY, Wang Y, Walsh TR, Yi LX, Zhang R, Spencer J, Doi Y, Tian G, Dong B, Huang $X$, et al. Emergence of plasmid-mediated colistin resistance mechanism MCR-1 in animals and human beings in China: a microbiological and molecular biological study. Lancet Infect Dis. 2016;16(2):161-8.

32. Landersdorfer CB, Ly NS, Xu H, Tsuji BT, Bulitta JB. Quantifying subpopulation synergy for antibiotic combinations via mechanism-based modeling and a sequential dosing design. Antimicrob Agents Chemother. 2013;57(5):2343-51.

33. Clinical and Laboratory Standard Institute. M100 performance standards for antimicrobial susceptibility testing. 28th ed. Wayne: Clinical and Laboratory Standards Institute; 2018

34. Odds FC. Synergy, antagonism, and what the chequerboard puts between them. J Antimicrob Chemother. 2003;52(1):1.

\section{Publisher's Note}

Springer Nature remains neutral with regard to jurisdictional claims in published maps and institutional affiliations.

Ready to submit your research? Choose BMC and benefit from:

- fast, convenient online submission

- thorough peer review by experienced researchers in your field

- rapid publication on acceptance

- support for research data, including large and complex data types

- gold Open Access which fosters wider collaboration and increased citations

- maximum visibility for your research: over $100 \mathrm{M}$ website views per year

At $\mathrm{BMC}$, research is always in progress.

Learn more biomedcentral.com/submissions 